\title{
Racial disparities in pedestrian-related injury hospitalizations in the United States
}

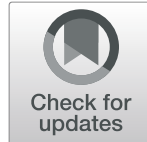

Cara Hamann ${ }^{1,2}$, Corinne Peek-Asa ${ }^{1,3^{*}}$ (i) and Brandon Butcher ${ }^{1,4}$

\begin{abstract}
Background: Racial/ethnic disparity has been documented in a wide variety of health outcomes, and environmental components are contributors. For example, food deserts have been tied to obesity rates. Pedestrian injuries are strongly tied to environmental factors, yet no studies have examined racial disparity in pedestrian injury rates. We examine a nationally-representative sample of pedestrian-related hospitalizations in the United States to identify differences in incidence, severity, and cost by race/ethnicity.

Methods: Patients with ICD diagnosis E-codes for pedestrian injuries were drawn from the United States Nationwide Inpatient Sample (2009-2016). Rates were calculated using the United States Census. Descriptive statistics and generalized linear regression were used to examine characteristics (age, sex, severity of illness, mortality rates, hospital admissions, length of stay, total costs) associated with hospitalizations for pedestrian injuries.
\end{abstract}

Results: The annual average of pedestrian-related deaths exceeded 5000 per year and hospitalizations exceeded 47,000 admissions per year. The burden of injury from pedestrian-related hospitalizations was higher among Black, Hispanic, and Multiracial/Other groups in terms of admission rates, costs per capita, proportion of children injured, and length of stay compared to Whites and Asian or Pacific Islander race/ethnicities. Compared to Whites, hospital admission rates were 1.92 (95\% Cl: 1.89-1.94) and 1.20 (95\% Cl: 1.19-1.21) times higher for Multiracial/Other and Blacks, respectively. Costs per capita (\$USD) were $\$ 6.30, \$ 4.14$, and $\$ 3.22$ for Multiracial/Others, Blacks, and Hispanics, compared to $\$ 2.88$ and $\$ 2.32$ for Whites and Asian or Pacific Islanders. Proportion of lengths of stay exceeding one week were larger for Blacks (26.4\%), Hispanics (22.6\%), Asian or Pacific Islanders (23.1\%), and Multiracial/Other (24.1\%), compared to Whites (18.6\%). Extreme and major loss of function proportions were also highest among Black (34.5\%) and lowest among Whites (30.2\%).

Conclusions: Results from this study show racial disparities in pedestrian injury hospitalization rates and outcomes, particularly among Black, Hispanic, and Multiracial/Other race/ethnicity groups and support population and system-level approaches to prevention. Access to transportation is an indicator for health disparity, and these results indicate that access to safe transportation also shows inequity by race/ethnicity.

Keywords: Walking, Race, Mortality, Health status disparities, Epidemiology

\footnotetext{
* Correspondence: Corinne-peek-asa@uiowa.edu

'University of lowa Injury Prevention Research Center, lowa City, IA, USA ${ }^{3}$ Department of Occupational and Environmental Health, University of lowa College of Public Health, 145 N. Riverside Dr, S143 CPHB, lowa City, IA 52242, USA

Full list of author information is available at the end of the article
}

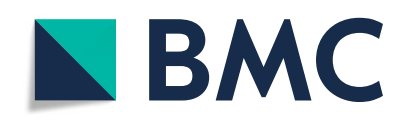

(- The Author(s). 2020 Open Access This article is licensed under a Creative Commons Attribution 4.0 International License, which permits use, sharing, adaptation, distribution and reproduction in any medium or format, as long as you give appropriate credit to the original author(s) and the source, provide a link to the Creative Commons licence, and indicate if changes were made. The images or other third party material in this article are included in the article's Creative Commons licence, unless indicated otherwise in a credit line to the material. If material is not included in the article's Creative Commons licence and your intended use is not permitted by statutory regulation or exceeds the permitted use, you will need to obtain permission directly from the copyright holder. To view a copy of this licence, visit http://creativecommons.org/licenses/by/4.0/. The Creative Commons Public Domain Dedication waiver (http://creativecommons.org/publicdomain/zero/1.0/) applies to the data made available in this article, unless otherwise stated in a credit line to the data. 


\section{Background}

Racial disparity has been well documented in a wide variety of health outcomes, ranging from infant mortality to asthma to diabetes to cardiovascular disease $[1,2]$. Characteristics of the built environment have been identified as an important social determinant of health disparity, as well as disparity related to race/ethnicity [3]. Examples include the relationships between food deserts and nutrition-related metabolic diseases, dilapidated neighborhoods and community violence, air pollution and mortality, and zip code characteristics with cancer and overall mortality $[4,5]$.

Environmental factors have been strongly tied to pedestrian injuries and deaths in all ages. Environmental risk factors include high speed roads, poor visibility, business density, wide roads, high traffic volume, and absence of pedestrian facilities (e.g. signals, refuge islands) [6-8]. Pedestrian fatalities have increased more than $50 \%$ in the past decade and currently account for $17 \%$ of all traffic deaths [3]. In 2018, over 180,000 pedestrians visited an emergency department for non-fatal injury treatment [4]. However, the burden of injury from pedestrian hospitalizations by race/ethnicity has not been previously estimated. Based on studies that tie racial inequity in health outcomes to the underlying environmental conditions associated with low resources [5], we hypothesize that non-whites in the US have higher rates of pedestrian injury death and hospitalization per 100,000 population compared to whites. The objective of this study was to identify differences by race/ethnicity for pedestrian mortality rates and to examine incidence, severity, and cost of pedestrian-related injury hospitalizations in a nationally-representative sample.

\section{Methods}

\section{Study design and data sources}

Data for mortality rates were from the Centers for Disease Control and Prevention Web-based Injury Statistics Query and Reporting System (WISQARS) [4] for the years of 2009 to 2016. Data for hospitalizations from 2009 to 2016 were from the US Nationwide Inpatient Sample (NIS). The NIS, a nationally representative database of patientlevel all-payer inpatient care, is part of the Healthcare Cost and Utilization Project, maintained by the Agency for Healthcare Research and Quality [9]. The NIS includes sample weights based on hospital characteristics (ownership/control, bed size, teaching status, urban/rural location, and region) that can be used to calculate nationally representative estimates. Hospitalizations with primary or secondary diagnosis external cause of injury e-codes corresponding to pedestrian injuries were included as part of the study sample. Data for rate denominators were from the United States Census total population for each race/ ethnic group. Populations for the Census Hispanic categories were aggregated to match the Hispanic definition used by the NIS. Native American was included in the Multiracial/Other category due to low counts.

\section{Study variables}

The primary dependent variable was total hospital costs. Hospital charges were converted to costs by using the cost-to-charge ratio files provided by the NIS and adjusted to inflation rates for in-hospital care for Q4 of 2016 based on Bureau of Labor Statistics data [10]. Cost per capita by race/ethnicity was computed as the estimated total hospital costs for each race/ethnic group divided by the corresponding total census population estimate of that group. This quantity is interpreted as the dollar amount burden of pedestrian injuries per person in each race/ethnicity group.

We also descriptively examined the following outcomes: length of stay (days), severity of illness, and mortality (died indicated in discharge disposition). Severity of illness was based on the Patient Diagnostic Related Group Severity of Illness variable in the NIS dataset, which includes the following categories: extreme, major, moderate, and minor loss of function.

The primary independent variable was race/ethnicity (Black, Hispanic, Asian or Pacific Islander, White, and Multiracial/Other). Native Americans and anyone identifying as multi-racial were included in the Multiracial/ Other category. Interactions between age, sex, and race were examined and it was determined by QIC that a model with only main effects for these variables best fit the data.

\section{Analysis}

National estimates of frequencies and proportions were calculated for all patient and hospital characteristics of interest (age, sex, severity of illness, mortality rates, hospital admissions, length of stay and total costs) by race/ ethnic group. Generalized Estimating Equations (GEE) based on the gamma distribution with an exchangeable working correlation matrix were used to estimate hospital costs per admission adjusted for patient and hospital level characteristics (age, sex, length of stay, severity of illness, income, payer source, indicator for ICD-9 vs. ICD-10, hospital region, \& hospital location/teaching status). All estimates incorporated NIS sampling weights and the NIS sampling design to provide nationally representative estimates and standard errors. SAS 9.4 was used for all statistical analyses.

\section{Results}

For the years 2009 to 2016, there were 40,576 deaths and 376,417 total estimated hospitalizations for pedestrianrelated injuries in the United States. Annually, that translates to an average of more than 47,000 pedestrian-related 
hospitalizations in the United States, accounting for an estimated $\$ 1.13$ billion in total hospital costs per year. The overall age-adjusted rate of pedestrian-related deaths increased from 1.31 in 2009 to 1.88 per 100,000 population in 2016 [4], while the estimated age-adjusted rate of hospitalizations decreased from 15.97 in 2009 to 12.40 per 100 , 000 population in 2016.

Pedestrian mortality rates per 100,000 population (Fig. 1) were highest for Multiracial/Others (2.44) and Blacks (2.78). Rates of hospital admissions (Fig. 1) were higher for Blacks (15.6) and Multiracial/Other (24.9) compared to Whites (13.0), Hispanics (11.8), and Asian or Pacific Islander (8.3) race/ethnicities.
Compared to Whites, the rate of hospital admissions were 1.92 and 1.20 times higher for Multiracial/Other and Blacks, respectively (Fig. 2). Whereas, the rate of hospital admissions were 36\% (Rate Ratio $=0.64$, 95\% $\mathrm{CI}=0.63-0.65$ ) and 9\% (Rate Ratio $=0.91,95 \% \mathrm{CI}=$ 0.90-0.92) lower for Asian or Pacific Islander and Hispanics, respectively.

Black, Hispanic, and Multiracial/Other groups had the highest costs per capita (Table 1). Pedestrian hospitalizations carry a burden of $\$ 4.14, \$ 3.22$, and $\$ 6.30$ per capita for Blacks, Hispanics, and Multiracial/Others, compared to $\$ 2.88$ and $\$ 2.32$ for Whites and Asian or Pacific Islanders. Higher proportions of children and

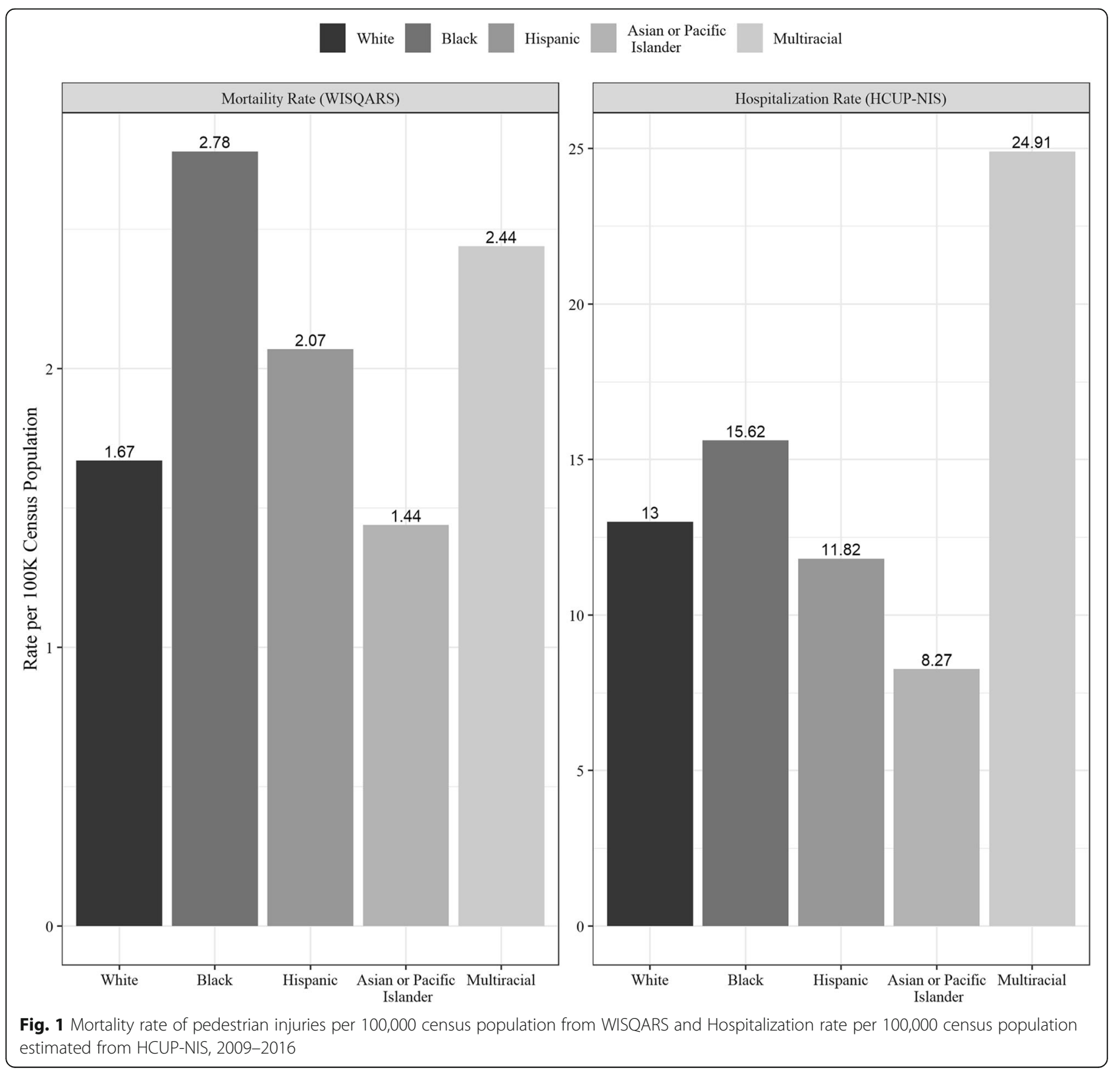




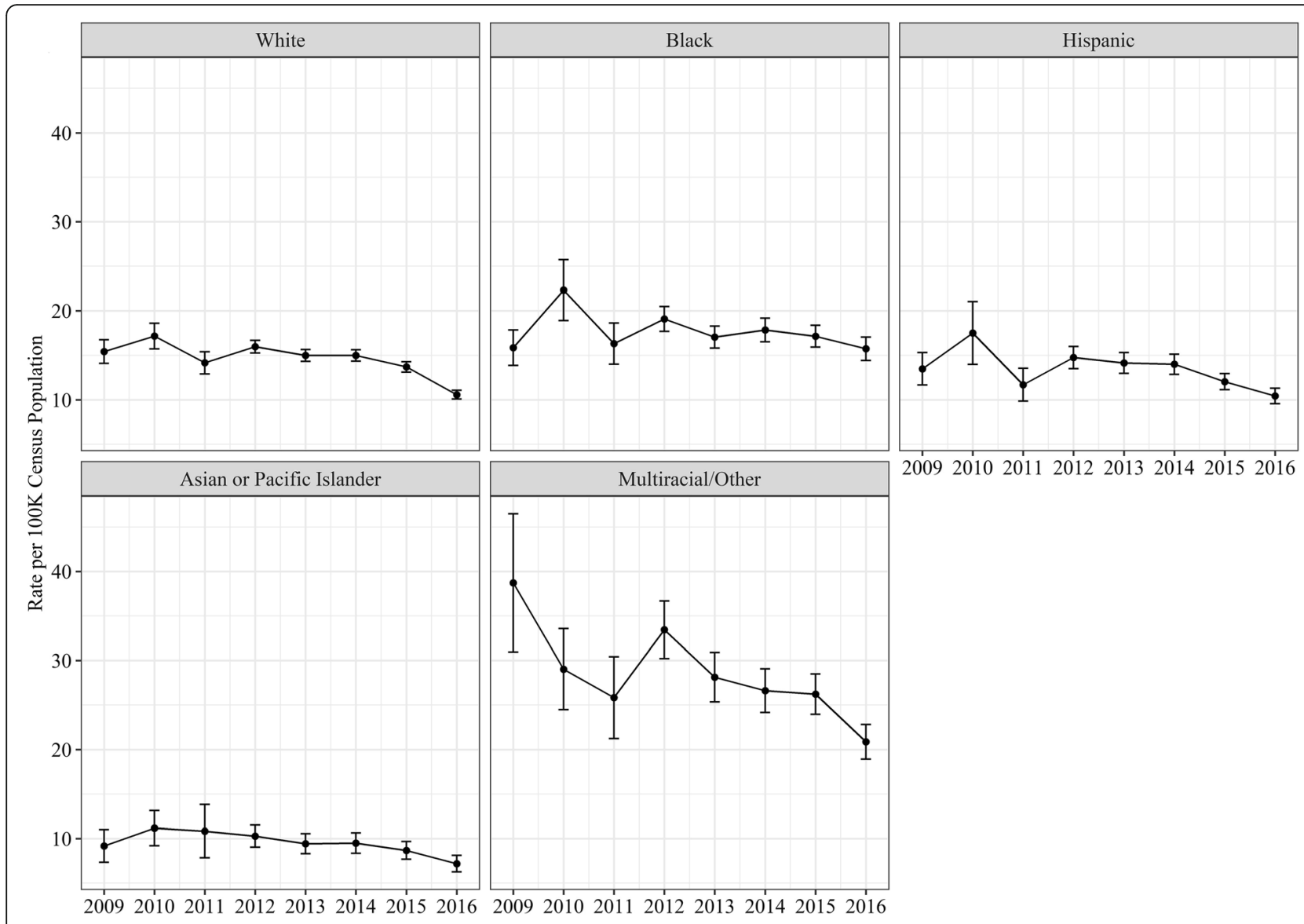

Fig. 2 Annual hospitalization admission rates by race estimated from HCUP-NIS, 2009-2016

young people (ages 24 and under) were injured among Black (32.5\%), Hispanic (35.8\%), and Multiracial/Other (30.7\%) groups, compared to White (21.9\%) and Asian or Pacific Islander $(22.8 \%)$. However, these age patterns are as expected, as young people make up a greater proportion of the population among those race/ethnic groups [11]. Compared to Whites, all other race/ethnicities had more lengths of stay exceeding one week. Extreme and major loss of function proportions were also higher among Blacks compared to other race/ethnicities.

Compared to Whites, all other race/ethnic groups had higher adjusted hospital costs (Table 2). Furthermore, adjusted hospital costs by each payer source (government, private, other) were lower for Whites compared to all other combinations of race and payer source, with the exception of self-pay.

\section{Discussion}

Racial disparities in pedestrian deaths and injuries were present in both hospitalization admission rates and outcomes. Mortality rates among Black, Hispanic, and Multiracial/Other and hospitalization admission rates among Black and Multiracial/Other race/ethnicity groups were particularly high compared to White and Asian or Pacific Islanders. The Black, Hispanic, and Multiracial/Other race/ethnic groups carry a larger burden of injury with increased hospital costs, cost per capita, severity of illness, and lengths of stay.

Results from this study align with a large body of literature related to racial disparities and health outcomes, which has consistently shown length of stay and cost disparities among Black, Hispanic, and Multiracial/Other race/ethnicities, compared to Whites [12,13]. A study of nearly 50,000 U.S. pedestrian deaths using CDC annual mortality data (1999-2015) found significant disparities in death rates by racial/ethnic groups, with higher rates among Blacks, Latinos, and Native Americans, compared to Whites [14], whereas our results showed similar racial/ethnic disparities in injury severity and burden of injury among pedestrian hospitalizations with higher costs per capita, longer lengths of stay, and increased mortality among Blacks, Hispanics, and Multiracial/Others, compared to Whites. Our results also align with previous research that has established links between race and 


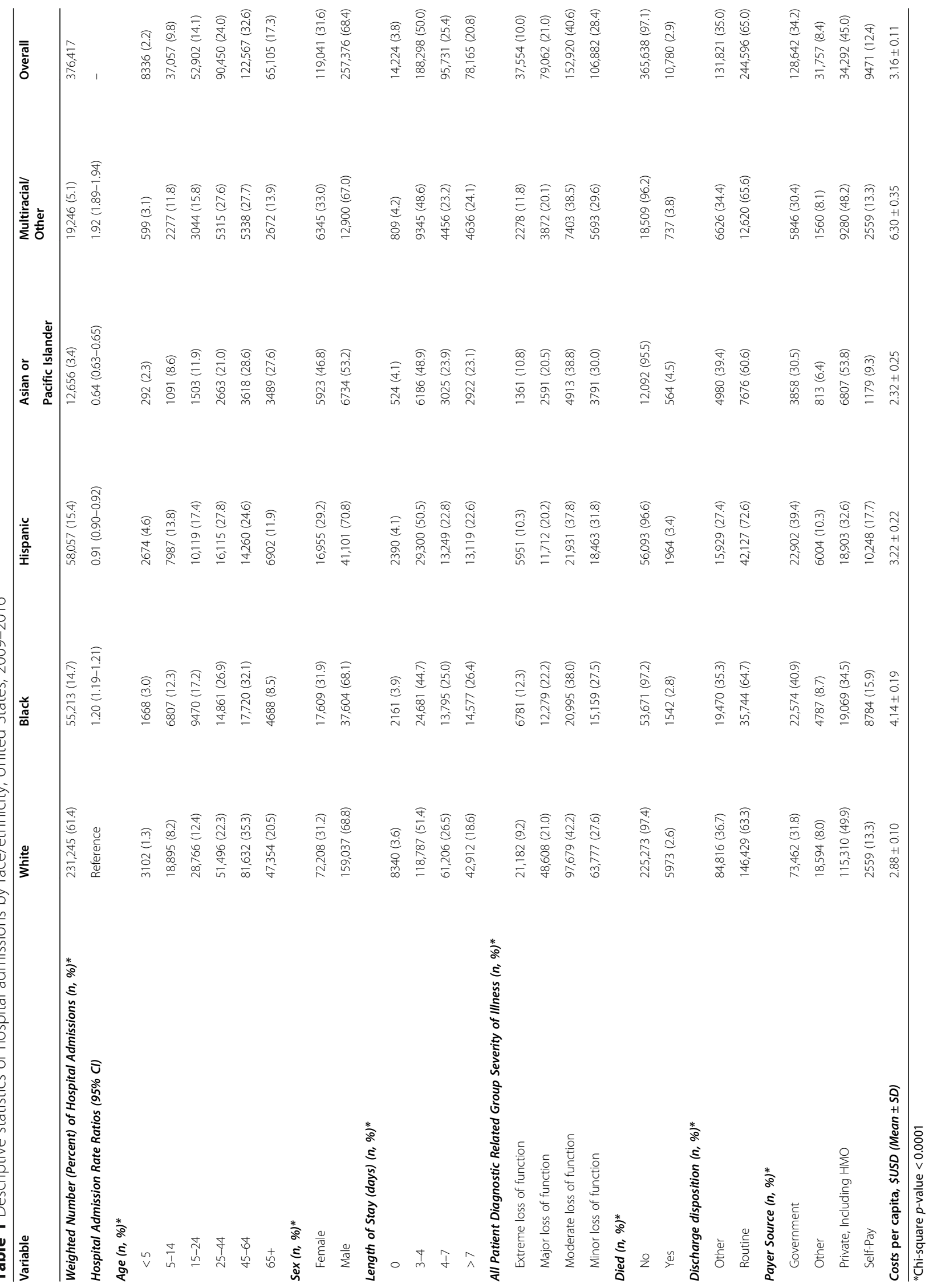


Table 2 Adjusted hospital costs per admission (95\% Cl) by race/ethnicity and by race/ethnicity by payer source

\begin{tabular}{|c|c|c|c|c|c|c|}
\hline Variable & White & Black & Hispanic & Asian or Pacific Islander & Multiracial/Other & Overall \\
\hline All Payer Sources & $\begin{array}{l}17,300 \\
(17,000-17,500)\end{array}$ & $\begin{array}{l}19,000 \\
(18,700-19,500)\end{array}$ & $\begin{array}{l}18,500 \\
(18,000-19,000)\end{array}$ & $\begin{array}{l}19,600 \\
(18,900-20,400)\end{array}$ & $\begin{array}{l}18,800 \\
(18,200-19,400)\end{array}$ & $\begin{array}{l}17,900 \\
(17,700-18,100)\end{array}$ \\
\hline \multicolumn{7}{|l|}{ Payer Source } \\
\hline Government & $\begin{array}{l}18,200 \\
(17,900-18,500)\end{array}$ & $\begin{array}{l}20,170 \\
(19,500-20,800)\end{array}$ & $\begin{array}{l}18,920 \\
(18,300-19,600)\end{array}$ & $\begin{array}{l}24,000 \\
(22,500-25,600)\end{array}$ & $\begin{array}{l}20,400 \\
(19,300-21,500)\end{array}$ & $\begin{array}{l}18,900 \\
(18,600-19,200)\end{array}$ \\
\hline Other & $\begin{array}{l}19,300 \\
(18,700-19,900)\end{array}$ & $\begin{array}{l}20,800 \\
(19,500-22,100)\end{array}$ & $\begin{array}{l}21,800 \\
(20,000-23,700)\end{array}$ & $\begin{array}{l}19,500 \\
(17,200-22,100)\end{array}$ & $\begin{array}{l}20,600 \\
(19,300-21,500)\end{array}$ & $\begin{array}{l}20,000 \\
(19,400-20,600)\end{array}$ \\
\hline Private, Including HMO & $\begin{array}{l}16,500 \\
(16,300-16,800)\end{array}$ & $\begin{array}{l}18,700 \\
(18,100-19,300)\end{array}$ & $\begin{array}{l}18,000 \\
(17,300-18,600)\end{array}$ & $\begin{array}{l}17,600 \\
(16,700-18,600)\end{array}$ & $\begin{array}{l}18,300 \\
(17,500-19,100)\end{array}$ & $\begin{array}{l}17,100 \\
(16,800-17,300)\end{array}$ \\
\hline Self-Pay & $\begin{array}{l}16,400 \\
(16,000-16,900)\end{array}$ & $\begin{array}{l}16,600 \\
(15,800-17,400)\end{array}$ & $\begin{array}{l}16,900 \\
(16,100-17,700)\end{array}$ & $\begin{array}{l}18,800 \\
(17,000-20,800)\end{array}$ & $\begin{array}{l}16,200 \\
(15,000-17,500)\end{array}$ & $\begin{array}{l}16,600 \\
(16,200-17,000)\end{array}$ \\
\hline
\end{tabular}

inequities in safety and accessibility of transportation, including walking, [15] and neighborhood social inequities, traffic volumes, road design, and road traffic injuries [6].

Accurate pedestrian exposure data by race/ethnicity are not available but are important for understanding the mechanisms behind these disparities. For example, differential exposure to walking (i.e., time spent walking and exposed to traffic) and risky pedestrian environments (e.g., higher traffic volumes, lack of pedestrian facilities) may contribute to these differences.

However, the specific mechanisms behind these disparities are complex, as evidenced within the existing literature. A UK-based study found higher rates of child pedestrian injuries among Blacks, regardless of area level deprivation, but found that area deprivation was an important factor among Whites and Asians with higher injury rates correlating with higher deprivation [16]. Those results suggest neither race/ ethnicity or area deprivation (e.g, built environment, socioeconomic factors) alone can adequately explain race/ethnicity differences. A study of US fatality data found higher rates of pedestrian and bicyclist fatalities among neighborhoods with high proportions of Black and Hispanic residents as compared to predominant White or Asian neighborhoods [17]. However, they also found predominant Black and Hispanic neighborhoods to be safer, overall, in terms of road traffic fatality rates compared to predominant non-Hispanic White neighborhoods [17]. Another possible factor includes racial bias, which has been found in driver yielding behavior at crosswalks [18-20].

Access to transportation is a recognized social determinant of health, but disparities and inequities in transportation access and safety have largely been overlooked, despite having important ramifications related to health and well-being (access to food, jobs, etc.) [21]. The persistence and variety of health outcomes which demonstrate racial disparity indicate that the focus of prevention would best be placed at the population-level and on systemsbased factors, rather than at the individual level or on issues related to race/ethnicity directly $[22,23]$. These factors include economic, built environment, and transportation policy changes and interventions. There is also evidence that focusing on the social environment and social determinants of health with a broad range of interventions, such as early childhood development programs, rental assistance programs, and de-concentration of public housing, can reduce racial disparities in health $[24,25]$.

Specific to reducing the burden from pedestrian injuries, interventions may include amending policies to resolve inequities in transportation access, improvements to the built environment to include pedestrian facilities (e.g., crosswalks, pedestrian signals), safety culture campaigns focused on geospatial areas at high risk, and geographic equity in road safety funding for both new projects and maintenance (e.g., repair and maintenance of roads and sidewalks).

This study is based on a nationally-weighted sample of hospital admissions, which should be strongly representative of the US population. Limitations include potential miscoding of pedestrian injuries, which can happen when the role of the injured person in the crash is not known at hospital admission, or miscoding of race and ethnicity. Lack of information about differential pedestrian exposure/activity by race/ethnicity, and particularly how built environments differ by race/ethnicity, are a limitation in making recommendations about prevention measures based on these findings.

Results from this study show that the burden of injury from pedestrian injuries is higher among non-Whites, which has important implications in development of prevention and intervention approaches as we work to combat the rising pedestrian fatality and injury toll in the United States. Detailed pedestrian exposure data are also needed to further examine possible mechanisms for these disparities.

\section{Conclusions}

This study adds to growing evidence of the ties between the physical environment and health. The persistence of racial disparities in health outcomes indicates priority for prevention approaches at the population and systems-level, as opposed to individual-level approaches. 
Thus, access to safe transportation should be integrated into transportation policy and infrastructure decisions.

\section{Acknowledgements}

Not applicable.

\section{Authors' contributions}

$\mathrm{CH}$ supervised manuscript development, participated in formulating the analytic design and interpretation, wrote sections of the manuscript, and in completing the final manuscript. BB participated in formulating the analytic design and interpretation, conducted analysis, drafted sections of the manuscript, and approved the final manuscript. CPA conceived the study question, participated in formulating the analytic design and interpretation, wrote sections of the manuscript, and completing the final version of the manuscript. All authors have approved the submitted version of the manuscript and are personally accountable for individual and overall contributions.

\section{Funding}

This research was funded in part by grant \# 1 R49 CE003095-01 of the National Center for Injury Prevention and Control/CDC.

\section{Availability of data and materials}

The National Inpatient Sample is available through the Healthcare Utilization Project of the Agency for Healthcare Research and Quality: https://www. hcup-us.ahrq.gov/nisoverview.jsp.

\section{Ethics approval and consent to participate}

This study was determined to be exempted from Human Subject Office review because the data are publicly available and de-identified. This determination was made by the University of lowa Human Subject Office.

\section{Consent for publication}

Not applicable.

\section{Competing interests}

Authors have no competing interests.

\section{Author details}

'University of lowa Injury Prevention Research Center, lowa City, IA, USA. ${ }^{2}$ Department of Epidemiology, University of lowa College of Public Health, Iowa City, IA, USA. ${ }^{3}$ Department of Occupational and Environmental Health, University of lowa College of Public Health, 145 N. Riverside Dr, S143 CPHB, lowa City, IA 52242, USA. ${ }^{4}$ Department of Biostatistics, University of lowa College of Public Health, lowa City, IA, USA.

Received: 8 December 2019 Accepted: 7 September 2020

Published online: 25 September 2020

\section{References}

1. Berry JG, Bloom S, Foley S, Palfrey JS. Health inequity in children and youth with chronic health conditions. Pediatrics. 2010;126(Suppl 3):S111-9.

2. Hauck FR, Tanabe KO, Moon RY. Racial and ethnic disparities in infant mortality. Semin Perinatol. 2011;35(4):209-20.

3. Governor's Highway Safety Association. Pedestrian traffic fatalities by state: 2019 preliminary data. https://www.ghsa.org/resources/Pedestrians20. Published 2020. Accessed 5/7/20.

4. Centers for Disease Control and Prevention. Web-based Injury Statistics Query and Reporting System (WISQARS). https://www.cdc.gov/injury/ wisqars/. Published 2019. Accessed May 7, 2020.

5. Thornton CM, Conway $\mathrm{TL}$, Cain $\mathrm{KL}$, et al. Disparities in pedestrian streetscape environments by income and race/ethnicity. SSM - Popul Health. 2016:2:206-16.

6. Morency P, Gauvin L, Plante C, Fournier M, Morency C. Neighborhood social inequalities in road traffic injuries: the influence of traffic volume and road design. Am J Public Health. 2012;102(6):1112-9.

7. Kraus JF, Hooten EG, Brown KA, Peek-Asa C, Heye C, McArthur DL. Child pedestrian and bicyclist injuries: results of community surveillance and a case-control study. Inj Prev. 1996;2(3):212-18.

8. Isola PD, Bogert JN, Chapple KM, Israr S, Gillespie TL, Weinberg JA. Google Street View assessment of environmental safety features at the scene of pedestrian automobile injury. J Trauma Acute Care Surg. 2019. (PMID: 31033887).

9. Agency for Healthcare Research and Quality. Healthcare Cost and Utilization Project (HCUP). HCUP Databases. http://www.hcup-us.ahrq.gov/nisoverview. jsp. Accessed May 22, 2020.

10. Bureau of Labor Statistics. Consumer Price Index. https://www.bls.gov/cpi/. Published 2019. Accessed.

11. United States Census Bureau. Population estimates by age, sex, race, and hispanic origin. https://www.census.gov/newsroom/press-kits/2018/ estimates-characteristics.html. Published 2017. Accessed July 17, 2019

12. Haider AH, Chang DC, Efron DT, Haut ER, Crandall M, Cornwell EE 3rd. Race and insurance status as risk factors for trauma mortality. Arch Surg. 2008; 143(10):945-9.

13. Ugowe FE, Jackson LR 2nd, Thomas KL. Racial and ethnic differences in the prevalence, management, and outcomes in patients with atrial fibrillation: a systematic review. Heart Rhythm. 2018;15(9):1337-45.

14. Kaufman EJ, Wiebe DJ. 103 Racial disparities in pedestrian deaths in the United States, 1999-2015. Injury Prevention. 2017;23(Suppl 1):A38-A39.

15. Bullard RD. Addressing urban transportation equity in the United States. Fordham Urban Law Journal. 2004:31(5):1183-210.

16. Steinbach R, Green J, Edwards P, Grundy C. 'Race' or place? Explaining ethnic variations in childhood pedestrian injury rates in London. Health Place. 2010;16(1):34-42.

17. Marshall WE, Ferenchak NN. Assessing equity and urban/rural road safety disparities in the US. J Urbanism. 2017;10(4):422-41.

18. Coughenour C, Clark S, Singh A, Claw E, Abelar J, Huebner J. Examining racial bias as a potential factor in pedestrian crashes. Accid Anal Prev. 2017; 98:96-100.

19. Kahn K, McMahon J, Goddard T, Adkins A. Racial bias in drivers' yielding behavior at crosswalks: Understanding the effect NITC-RR-869, Portland: Transportation Research and Education Center (TREC). https://doi.org/10. 15760/trec.185. 2017.

20. Goddard T, Kahn KB, Adkins A. Racial bias in driver yielding behavior at crosswalks. Transport Res F: Traffic Psychol Behav. 2015;33:1-6.

21. Sanchez TW, Stolz R, Ma JS. Inequitable effects of transportation policies on minorities. Transp Res Rec. 2004;1885(1):104-10.

22. Williams DR, Braboy Jackson P. Social sources of racial disparities in health. Health Affairs. 2005;24(2):325-34.

23. National Academies of Sciences, Engineering, and Medicine; Health and Medicine Division; Board on Population Health and Public Health Practice; Committee on Community-Based Solutions to Promote Health Equity in the United States. The root causes of health inequity. In: Baciu A, Negussie Y, Aea G, eds. Communities in action: pathways to health equity. Washington, DC: National Academies Press; 2017.

24. Williams DR, Costa MV, Odunlami AO, Mohammed SA. Moving upstream: how interventions that address the social determinants of health can improve health and reduce disparities. J Public Health Manag Pract. 2008;14 Suppl(Suppl):S8-17.

25. Thornton RL, Glover CM, Cené CW, Glik DC, Henderson JA, Williams DR. Evaluating strategies for reducing health disparities by addressing the social determinants of health. Health Aff (Millwood). 2016:35(8):1416-23.

\section{Publisher's Note}

Springer Nature remains neutral with regard to jurisdictional claims in published maps and institutional affiliations.

Ready to submit your research? Choose BMC and benefit from

- fast, convenient online submission

- thorough peer review by experienced researchers in your field

- rapid publication on acceptance

- support for research data, including large and complex data types

- gold Open Access which fosters wider collaboration and increased citations

- maximum visibility for your research: over $100 \mathrm{M}$ website views per year

At BMC, research is always in progress.

Learn more biomedcentral.com/submission 